\title{
Feasibility of using automatic milking system data from commercial herds for genetic analysis of milkability
}

\author{
C. Carlström, ${ }^{* 1}$ G. Pettersson,† K. Johansson,‡ E. Strandberg, ${ }^{*}$ H. Stålhammar, $§$ and J. Philipsson* \\ *Department of Animal Breeding and Genetics, Swedish University of Agricultural Sciences, PO Box 7023, SE-750 07 Uppsala, Sweden \\ †Department of Animal Nutrition and Management, Swedish University of Agricultural Sciences, SE-753 23 Uppsala, Sweden \\ ¥Växa Sweden, PO Box 7023, SE-750 07 Uppsala, Sweden \\ §Viking Genetics, PO Box 64, SE-532 21 Skara, Sweden
}

\section{ABSTRACT}

The objective of this study was to investigate how useful data from automatic milking systems used in commercial herds are for genetic analysis of milkability traits. Data were available from 4,968 Swedish Holstein and Swedish Red cows over a span of 5 yr (2004-2009) from 19 herds. The analyzed milkability traits were average flow rate, box time, milking interval, and number of milkings per day. Variance components were estimated for genetic, permanent environmental, and residual effects in first and later (second and third) lactations, and were used for estimation of heritabilities and repeatablilites. The experiences of the data quality and editing procedures showed that almost half of the data and about a quarter of the cows had to be excluded from the analyses due to incomplete or inconsistent information. However, much more data are available than is needed for accurate genetic parameter estimations. For the genetic analysis, a repeatability animal model was used that included the fixed effects of herd, year and season, lactation month, and milk yield. The repeatability coefficients were at a high level: highest for average flow rate, with estimates between 0.8 and 0.9 . The estimated heritability coefficients were in the range of 0.37 to $0.48,0.21$ to $0.44,0.09$ to 0.26 , and 0.02 to 0.07 for average flow rate, box time, milking interval, and number of milkings, respectively. The results from the present study unraveled large genetic variation in milkability traits. The genetic parameter estimates were well in agreement with previous studies of milkability, which proves the feasibility of using data from automatic milking systems for genetic analysis.

Key words: milkability, automatic milking system, genetic parameter

Received October 2, 2012.

Accepted April 14, 2013.

${ }^{1}$ Corresponding author: caroline.carlstrom@slu.se

\section{INTRODUCTION}

In Sweden, $19 \%$ of the dairy herds used automatic milking systems (AMS) in 2012, corresponding to $28 \%$ of the cows (N.-E. Larsson, Växa Sweden, Stockholm, Sweden, personal communication). To ensure good economy with AMS, the milking box needs to be efficiently used so that a maximum amount of milk is produced per robot per day. Milk yield per cow and the total time each cow spends in the milking box are the traits most important to achieve this. Milk flow rate and milking time are the most common measures of milkability traits. Castro et al. (2012) concluded that the 2 variables number of cows and milk flow rate had the greatest influence on daily milk yield per AMS.

Milkability has in the last decades often been measured subjectively, where the farmers have scored the animals on a scale from slow-milking to fast-milking cows. Heritability estimates from studies looking at subjectively scored milkability are in the range of 0.1 to 0.2 (e.g., Meyer and Burnside, 1987; Lawstuen et al., 1988; Sewalem et al., 2011). As the dairy herds increase in size, and less personnel time is spent per cow, the accuracy in evaluations based on subjective data will likely decrease. During recent years, several researchers showed results from genetic analyses based on objectively measured milkability (milk flow rate or milking time), where they obtained higher heritabilities (in the range of 0.2 to 0.5 ) compared with subjective measurements (e.g., Vicario et al., 2006; Gäde et al., 2007; Laureano et al., 2012). In most published studies, however, the results are based on single or a few milkability measurements per cow. Now, with the increased use of AMS, the opportunity to more easily capture objective milkability data is a reality. Automatic milking systems provide repeated measurements of milkability traits, including milk flow rate, milking time, box time, milking interval, and number of milkings per day. Only a few reports exist on genetic analyses of repeatedly measured milkability from research herds with AMS (Gäde et al., 2006; Løvendahl et al., 2011) and even less is known about using these kinds of records from commercial AMS herds. 
Automatic milking systems are equipped with in-line milk sensors that can measure milk flow rate and milking time or box time and automatically store them in a local database. This opens up an opportunity for genetic improvement of milkability traits, provided that the AMS data generate reasonable genetic parameters. The issues that need to be addressed are to decide which measures of milkability are the most suitable, which observations should be used, how to handle the editing of the data, and how many observations are needed for analysis of the traits to obtain accurate parameters.

The aim of this study was to investigate the usefulness of AMS data from commercial herds having the 2 major dairy breeds in Sweden for genetic analysis of various milkability traits, including those specific for AMS. The number of useful records, estimates of heritability, repeatability, and permanent environmental effects were used to assess the feasibility of using AMS data for genetic analysis.

\section{MATERIALS AND METHODS}

Data for the study were provided from 19 commercial dairy herds in Sweden using DeLaval automatic milking systems [voluntary milking system (VMS); DeLaval, Tumba, Sweden]. Complementary information about included cows was provided by Växa Sweden. The original data set consisted of observations from fall 2004 to spring 2009 of 4,968 Swedish Holstein (SH) and Swedish Red (SR) cows, with a total of 5,115,363 milkings. Both breeds were represented in 13 of the herds. In total, 17 herds had SH and 15 herds had SR cows.

Information about each milking since the installation of the AMS was stored in a local database and was downloaded for this study. Registrations of importance were cow identification number, date and time for entering (begin time) and leaving (end time) the milking box, average milk flow rate (AFR; $\mathrm{kg} / \mathrm{min})$, peak flow rate (PFR; $\mathrm{kg} / \mathrm{min})$, time spent in the milking box (BT; min), milking interval (MI; h), milking frequency (NoM), and milk yield (MY; kg). Flow rates and MY were measured per udder quarter in the AMS and were added to 1 record per cow and trait for each milking. The AFR was defined by the AMS as the average of the milk flows measured for each quarter within 1 milking. The milking time (MT) was calculated in minutes as the ratio between MY and AFR for each udder quarter separately. To the fore udder quarters, $30 \mathrm{~s}$ were added to consider time for attachment of teat cups. The MT for the cow was then defined as the longest MT of these 4 values. The BT was calculated in minutes as the difference between the 2 variables begin time and end time. The MI was calculated in hours as the dif- ference between the begin time for the present milking and the begin time for the previous milking. The NoM was defined as the number of milkings per cow per 24 h. The variables AFR, BT, MI, and NoM were used as measures of milkability. One record per cow and milking was available for AFR, BT, and MI. The NoM was given per $24 \mathrm{~h}$. To get 1 record for every milking, an alternative definition was also used for NoM, where NoM was defined as 24 divided by MI, but it yielded the same results as for MI and is not further included in the paper. In preliminary analyses, PFR and MT were also included but almost identical results were obtained as for AFR and BT, and they were thus excluded from further analysis, except for presentation of descriptive statistics.

\section{Data Editing}

The process of editing the data is shown in Figure 1. To connect each milkability record from the AMS with the official identification number, the pedigree of each cow, its parity number, and lactation stage, the data set from the dairy herds was merged with information from the official milk-recording scheme run by Växa Sweden. As the dairy farmers do not need to use the same identification system for the cows in the AMS as is used in the national recording scheme, there was a loss of data when merging the 2 data sets. This problem was probably specific for this data set, as the data were collected during a period with fast-increasing herd sizes and new milking systems. The resulting data set included 4,080 cows $(82 \% ; 2,199 \mathrm{SH}$ and 1,881 SR cows), with milkability records from at least 1 of the first 3 lactations.

Records from d 8 to 330 after calving were included. All records were excluded that were identified by the AMS as incomplete milkings (i.e., if the milk yield in the present milking was less than $70 \%$ of the expected yield in at least 1 quarter, based on previous milkings). All records where the previous milking was identified as incomplete were also excluded, as they may have been influenced by that previous milking. Furthermore, all records where the AMS identified a removal ("kick off") of the milking cluster from any quarter during milking were excluded. In total, $21 \%$ of the records were excluded due to incomplete milkings and the effects of the following milking. Records that were clearly inconsistent with the normal patterns regarding the variation in MI, BT, milk yield, and AFR were also excluded. Milking intervals shorter than $5 \mathrm{~h}$ or longer than $30 \mathrm{~h}$ were excluded, as well as BT records shorter than 1 min or longer than 20 min, and records lacking a milk yield observation. The AFR records were excluded if they exceeded $8.5 \mathrm{~kg} / \mathrm{min}$ for $\mathrm{SH}$ and $7.0 \mathrm{~kg} / \mathrm{min}$ for 


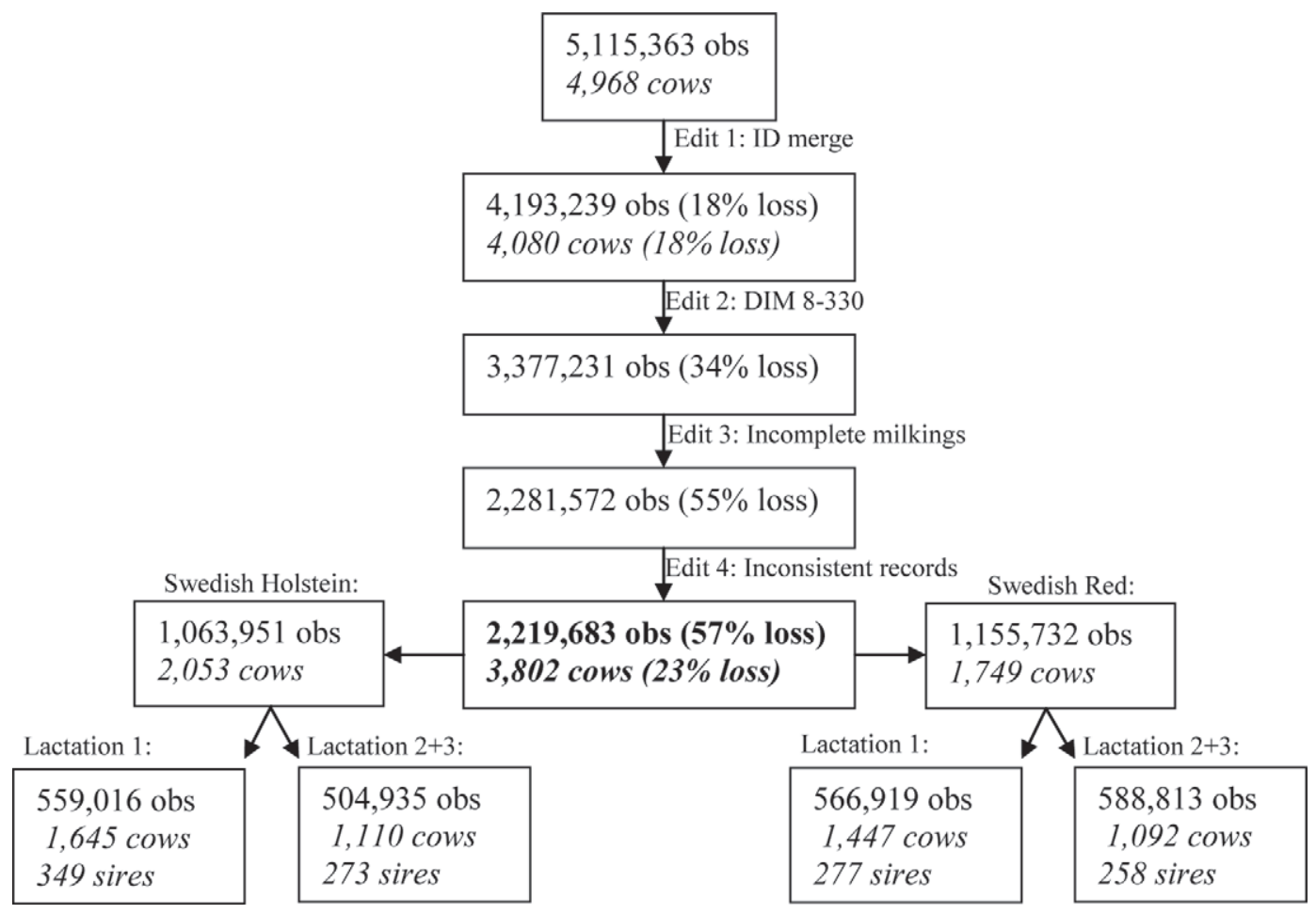

Figure 1. Summary of the editing process. The accumulated loss of records and cows after each editing step is given within parentheses. Edit 1: automatic milking system (AMS) data are merged with information on identification and pedigree from Växa Sweden. Edit 2: inclusion only of DIM 8 to 330. Edit 3: exclusion of records due to incomplete milkings. Edit 4: exclusion of outliers for milking interval, box time, and average flow rate. obs $=$ observations.

SR, as such values were considered a result of faulty meter recording. In total, only $2 \%$ of the records were excluded due to inconsistencies.

The editing process differed for NoM compared with the other milkability traits. To obtain accurate measurements of this trait, observations from incomplete milkings and observations on AFR and BT defined as outliers also needed to be included. For NoM, only the edit 1 and edit 2 steps described in Figure 1 were done, with the addition of excluding observations clearly inconsistent with the general pattern regarding MI as previously described. For SH, this resulted in 353,460 remaining first-lactation observations and 318,622 later (second and third) lactation observations, and for SR the corresponding figures were 323,572 and 330,163 observations. For estimations of descriptive statistics, MI was treated in the same way as NoM, whereas for the genetic analyses only, observations that remained after the whole editing process were included.

In total, data editing resulted in a sizable loss: $57 \%$ of the observations and $23 \%$ of the cows. The pattern of loss was similar for the 2 breeds and for first-lactation records compared with records from later lactations. The loss of information in edit $2(16 \%$ loss of observations), depending on lactation stage, where only DIM 8 to 330 were included, does however not reflect the quality of the AMS data but is a common restriction done for breeding value estimations. As several years were included in the study, many cows appeared in both first and later lactations.

Finally, 2,053 $\mathrm{SH}$ cows from 420 sires and 1,749 SR cows from 339 sires were available for the genetic analysis. The pedigree information contained sires and dams in 3 generations. Noninformative individuals in the pedigrees were removed with the DMU Trace program (Madsen, 2010). In total, 7,551 and 5,283 animals were included in the pedigree file for $\mathrm{SH}$ in first and later parities, respectively, and 5,980 and 4,840 animals were included in the pedigree file for SR in first and later parities, respectively. For SH, 186 sires had 2 or more first-lactation daughters, whereas the corresponding figure for SR was 139. More details of the progeny structure are shown in Table 1.

The traits were checked for normality by visual inspection of quantile-quantile (Q-Q) plots. The AFR and NoM fitted well to normal distributions, although the NoM classes were limited. The BT and MI showed more skewed distributions. The distribution of the residuals from the analysis based on the statistical model described in a following paragraph was examined for all 
Table 1. Number of cows and their sires for Swedish Holstein and Swedish Red cows in different lactations (Lact)

\begin{tabular}{|c|c|c|c|c|c|c|}
\hline \multirow[b]{2}{*}{ Item } & \multicolumn{3}{|c|}{ Swedish Holstein } & \multicolumn{3}{|c|}{ Swedish Red } \\
\hline & Lact 1 & Lact 2 & Lact 3 & Lact 1 & Lact 2 & Lact 3 \\
\hline No. of cows & 1,645 & 981 & 531 & 1,447 & 983 & 561 \\
\hline \multicolumn{7}{|l|}{ No. of sires } \\
\hline Total & 349 & 250 & 178 & 277 & 229 & 170 \\
\hline 2 or more daughters & 186 & 134 & 82 & 139 & 103 & 70 \\
\hline 10 or more daughters & 42 & 21 & 12 & 32 & 24 & 14 \\
\hline
\end{tabular}

traits and shown to have normal distributions. Thus, the records of all 4 traits were well suited for analysis with linear models.

\section{Statistical Model and Estimation of Genetic Parameters}

The 2 breeds were analyzed separately because they were previously shown to differ in milk flow rate (Lundberg, 1974). Milkability traits in first and later (second and third) lactations were, for this study, considered to be different traits and therefore analyzed in 2 separate analyses. Univariate analyses of AFR, BT, MI, and NoM were used, with the aim of obtaining estimates of variance components, repeatabilities, and heritabilities.

The repeatability model used was as follows:

$$
\begin{aligned}
y_{i j k l}= & \mu+\mathrm{HYS}_{i}+\mathrm{LM}_{j}+p e_{k}+a_{k} \\
& +\beta_{j} \mathrm{MY}(\mathrm{LM})_{i j k l}+e_{i j k l},
\end{aligned}
$$

where $y_{i j k l}$ is the AFR ( $\left.\mathrm{kg} / \mathrm{min}\right), \mathrm{BT}(\mathrm{min})$, or MI (h) of cow $k$ for a particular milking, or the NoM of cow $k$ for a particular DIM; $\mu$ is the overall mean; $\mathbf{H Y S}_{i}$ is the fixed effect of the $i$ th combination of herd $(1-17 ; 1-15)$ with year (2004-2009) and season of observation (January-December, 1-12); $\mathbf{L} \mathbf{M}_{j}$ is the fixed effect of the $j$ th lactation month (1-11); $p e_{k}$ is the random permanent environmental effect of cow $k$ to account for repeated measurements within cow: $\sim \mathrm{ND}\left(0, \mathbf{I} \sigma_{\text {pe }}^{2}\right)$, where $\mathrm{ND}$ is normally distributed, $\mathbf{I}$ is an identity matrix, and $\sigma_{\mathrm{pe}}^{2}$ is the permanent environment variance; $a_{k}$ is the random additive genetic effect of cow $k: \sim \mathrm{ND}\left(0, \mathbf{A} \sigma_{\mathrm{a}}^{2}\right)$, where $\mathbf{A}$ is the additive genetic relationship matrix and $\sigma_{\mathrm{a}}^{2}$ is genetic effects variance; $\beta_{\mathrm{j}} \mathrm{MY}(\mathrm{LM})_{i j k l}$ is the effect of MY for the particular milking $l$ of cow $k$ in $\mathrm{HYS}_{i}$ and $\mathrm{LM}_{j}$ as a fixed linear covariate nested within $\mathrm{LM}_{j}$, thus resulting in 11 regression coefficients, or when analyzing NoM, $\beta_{1} \mathrm{MY}(\mathrm{LM})_{i j k}$ is the effect of the total MY for the particular DIM of cow $k$ in $\mathrm{HYS}_{i}$ and $\mathrm{LM}_{j}$ as a linear covariate nested within $\mathrm{LM}_{j}$, thus resulting in 11 regression coefficients; and $e_{i j k l}$ is the random residual effect belonging to observation $y_{i j k l}: \sim \operatorname{IND}\left(0, \sigma_{\mathrm{e}}^{2}\right)$, where $\sigma_{\mathrm{e}}^{2}$ is the residual error variance. Covariances between all random effects (a, pe, and e) were assumed to be zero. The same model was used for the analyses of later lactations, with the addition of lactation number 2 or 3 as a fixed effect, and pe was now across lactations.

Milk yield at the observation of flow rate, or other milkability traits, was included in the model because yield is an important factor influencing flow rate due to its effect on udder pressure (Johansson 1961). According to Gäde et al. (2006), the variation in milkability from day to day makes it necessary to consider the day of observation in linear models for analyzing milkability. However, one reason for that conclusion could derive from the fact that they adjusted for milking interval instead of milk yield in their analyses. In the present study, models where stage of lactation was handled in different ways were compared in preliminary analyses before finalizing the repeatability model for estimation of genetic parameters.

Variance components were estimated using the average information algorithm (Jensen et al., 1997) for restricted maximum likelihood (REML) with the DMU software (Madsen and Jensen, 2007). The heritabilities were calculated as $\sigma_{\mathrm{a}}^{2} / \sigma_{\mathrm{p}}^{2}$, where $\sigma_{\mathrm{p}}^{2}$ is the phenotypic variance and $\sigma_{\mathrm{p}}^{2}=\sigma_{\mathrm{pe}}^{2}+\sigma_{\mathrm{a}}^{2}+\sigma_{\mathrm{e}}^{2}$. The proportion of variance due to the permanent environmental effect to the total phenotypic variance $\left(\mathrm{c}_{\mathrm{pe}}^{2}\right)$ was calculated as $\sigma_{\mathrm{pe}}^{2} / \sigma_{\mathrm{p}}^{2}$ and the repeatabilities $(\mathrm{t})$ across all milkings were calculated as $\left(\sigma_{\mathrm{pe}}^{2}+\sigma_{\mathrm{a}}^{2}\right) / \sigma_{\mathrm{p}}^{2}$. Standard errors of heritabilities were obtained by Taylor series expansions based on the standard error of the variance components estimated in the DMU software.

\section{RESULTS}

Means and variation of the traits included in the genetic analyses, and also for PFR and MT, are shown in Table 2 . The variation in milkability traits was large. Coefficients of variation were similar for both breeds and across parities, ranging from 28 to $31 \%$ for $\mathrm{SH}$ and 
Table 2. Mean, SD, minimum (Min), and maximum (Max) values for average flow rate (AFR), peak flow rate (PFR), box time (BT), milking time (MT), milking interval (MI), number of milkings (NoM), and milk yield in first and later lactations for Swedish Holstein and Swedish Red cows

\begin{tabular}{|c|c|c|c|c|c|c|c|c|c|c|}
\hline Item & \multicolumn{5}{|c|}{ Lactation 1} & \multicolumn{5}{|c|}{ Lactation $2+3$} \\
\hline \multicolumn{11}{|l|}{ Swedish Holstein } \\
\hline PFR (kg/min) & 559,016 & 5.32 & 1.35 & 0.72 & 10.98 & 504,935 & 5.93 & 1.47 & 0.60 & 11.00 \\
\hline $\mathrm{BT}$ (min) & 559,016 & 7.19 & 2.02 & 2.73 & 19.95 & 504,935 & 7.54 & 2.14 & 2.98 & 19.92 \\
\hline MT (min) & 559,016 & 4.58 & 1.61 & 1.03 & 16.54 & 504,935 & 4.97 & 1.82 & 0.69 & 19.50 \\
\hline Yield (kg) & 559,016 & 12.10 & 3.19 & 1.04 & 34.16 & 504,935 & 14.92 & 4.48 & 1.00 & 34.99 \\
\hline \multicolumn{11}{|l|}{ Swedish Red } \\
\hline $\operatorname{AFR}(\mathrm{kg} / \mathrm{min})$ & 566,919 & 3.12 & 0.87 & 0.48 & 6.96 & 588,813 & 3.35 & 0.90 & 0.36 & 6.96 \\
\hline PFR (kg/min) & 566,919 & 4.77 & 1.11 & 0.84 & 9.00 & 588,813 & 5.06 & 1.15 & 0.78 & 9.00 \\
\hline $\mathrm{BT}(\min )$ & 566,919 & 7.46 & 2.08 & 2.57 & 19.98 & 588,813 & 7.84 & 2.21 & 2.63 & 19.98 \\
\hline $\operatorname{MT}(\min )$ & 566,919 & 4.83 & 1.68 & 1.08 & 15.93 & 588,813 & 5.19 & 1.89 & 0.09 & 15.90 \\
\hline MI (h) & 808,354 & 9.58 & 2.78 & 5.00 & 29.97 & 803,284 & 9.70 & 2.94 & 5.00 & 29.98 \\
\hline
\end{tabular}

from 27 to $30 \%$ for SR. For both breeds, AFR, PFR, $\mathrm{BT}, \mathrm{MT}$, and MI increased from first to later lactations, whereas the NoM decreased slightly. In general, the differences between lactations were somewhat bigger for SH than for SR.

\section{Choice of Statistical Model}

Before finalizing the model for estimation of genetic parameters, different models where stage of lactation was handled in different ways were compared. The alternatives were lactation month or lactation week treated as fixed effects, or DIM treated as a fixed regression. The results from the preliminary analyses were practically the same regardless of the choice of definition of stage of lactation (Table 3). Therefore, we chose to use lactation month as a fixed effect to account for stage of lactation in the statistical model.
Inclusion of MI in the statistical model instead of MY was also tested, but comparisons of coefficients of determination and residual variance values $\left(\sigma_{\mathrm{e}}^{2}\right)$ for the different models (Table 3 ) clearly showed that MY was the best choice. Thus, MI could be analyzed as a trait rather than a factor to adjust milkability for. In the final model, the effect of MY was nested within the effect of LM because the results from the preliminary analyses showed that the size of the regression coefficient for MY varied slightly across LM, especially for NoM.

\section{Fixed Effects and Variance Components}

The included effects of HYS, LM, and MY were all found to be significant $(P<0.001)$ for all 4 analyzed milkability traits. The LM effects showed a pattern with highest flow rates toward the end of lactation when adjusted for milk yield in first lactation for both breeds,

Table 3. Comparison of models $\left[\mathrm{R}^{2}\right.$, residual error variance $\left(\sigma_{\mathrm{e}}^{2}\right)$, error variance in percentage of total variance of the observations $\left(\sigma_{\mathrm{e}}^{2} / \sigma_{\text {Tot }}^{2}\right)$, heritability $\left(\mathrm{h}^{2}\right)$, and $\log$-likelihood $\left.(-2 \log \mathrm{L})\right]$ when different factors are included to explain the variation in average flow rate for Swedish Holstein in first lactation

\begin{tabular}{lccccc}
\hline Model factors $^{1}$ & $\mathrm{R}^{2}$ & $\sigma_{\mathrm{e}}^{2}$ & $\sigma_{\mathrm{e}}^{2} / \sigma_{\text {Tot }}^{2}$ & $\mathrm{~h}^{2}$ & $-2 \operatorname{LogL}$ \\
\hline HYS + LM & 0.155 & 0.137 & 11.7 & 0.33 & 492,009 \\
HYS + LW & 0.156 & 0.137 & 11.6 & 0.31 & 488,608 \\
HYS + $\beta_{1}$ DIM & 0.151 & 0.141 & 12.0 & 0.30 & 507,612 \\
HYS + LM $+\beta_{2}$ MI & 0.156 & 0.131 & 11.2 & 0.33 & 466,236 \\
HYS + LM $+\beta_{3}$ MY & 0.194 & 0.121 & 10.3 & 0.37 & 421,208 \\
HYS + LM $+\beta_{j}$ MY (LM) & 0.194 & 0.121 & 10.2 & 0.37 & 419,289 \\
\hline
\end{tabular}

${ }^{1}$ HYS $=$ fixed effect of combination of herd with year and season of observation; LM $=$ fixed effect of lactation month; LW = fixed effect of lactation week; $\beta=$ regression of average flow rate on DIM (1), milking interval (2), milk yield (3), or milk yield nested within lactation month $(j)$; MI = milking interval; MY = milk yield. 
whereas in later lactations, the LM effects showed a pattern with highest flow rates in the middle of the lactations. The effect of MY was measured as the coefficient of regression, showing a value of $0.06 \mathrm{~kg} / \mathrm{min}$ in AFR per kilogram increase in MY for $\mathrm{SH}$ and $0.05 \mathrm{~kg} /$ min for SR in first and later lactations. Corresponding values for BT were an increase of $0.27 \mathrm{~min}(0.23 \mathrm{~min})$ per kilogram of increased milk yield for $\mathrm{SH}$ and 0.33 min $(0.30 \mathrm{~min})$ for $\mathrm{SR}$ in first (and later) lactations.

Variance components and other parameters of the analyzed milkability traits are summarized in Table 4. The permanent environmental variation was large for all traits. In relation to the total phenotypic variation, the permanent environmental variation was $52 \%$ for AFR in the first lactations of both breeds, whereas it was 55 and $40 \%$ for BT, 49 and $68 \%$ for MI, and 12 and $19 \%$ for NoM for SH and SR, respectively. The permanent environmental variation decreased between first and later lactations for all traits except for NoM of SR. The decrease in permanent environmental variation between lactations was bigger for SR than for SH.

To receive a variance component for the HYS effect, HYS was alternatively analyzed as a random effect for AFR, resulting in a value of 0.06 for both SH and SR in first lactation (i.e., about a tenth compared with the permanent environmental variation among individual cows).

The heritability estimates ranged from moderate to high for AFR (0.37-0.48) and BT (0.21-0.44), and from low to moderate $(0.09-0.26)$ for MI, whereas the estimates were low for NoM $(0.02-0.07)$. The changes between lactations were not significant for AFR and BT. For MI, heritabilities changed in opposite directions for the 2 breeds. For NoM, lower heritabilities were obtained in later lactations of both breeds.

The repeatability followed the same pattern for both breeds. It was highest for AFR (0.85-0.89), followed by BT (0.69-0.89), MI (0.61-0.77), and NoM (0.17-0.23). As for the environmental variance, the repeatability values also decreased between first and later parities, but for AFR the differences were small.

\section{DISCUSSION}

This study aimed ultimately to prove the feasibility of using objectively measured data directly collected from commercial herds with AMS for estimation of genetic parameters of traditional and new milkability traits. Important issues for consideration were how to edit the data and the losses for various reasons, choice of statistical model, phenotypic and genetic parameters, and finally the choice of suitable traits to reflect milkability of cows in AMS. The results from the present study based on a repeatability model unraveled large genetic variation in milkability traits, with genetic parameter estimates well in agreement with previous studies of milkability.

\section{Phenotypic Characterization of Milkability Traits}

The uniqueness of this study was that it is one of the few studies where information about milk flow rate

Table 4. Variance components due to genetic effects $\left(\sigma_{\mathrm{a}}^{2}\right)$, permanent environment $\left(\sigma_{\mathrm{pe}}^{2}\right)$, and random residual effects $\left(\sigma_{\mathrm{e}}^{2}\right)$, and heritabilities $\left(\mathrm{h}^{2}\right)$, proportion of the permanent environmental variance to phenotypic variance $\left(\mathrm{c}_{\mathrm{pe}}^{2}\right)$, and repeatabilities $(\mathrm{t})$ for milkability traits in first and later lactations (Lact) for Swedish Holstein and Swedish Red cows (SE in parentheses)

\begin{tabular}{|c|c|c|c|c|c|c|c|}
\hline \multicolumn{8}{|c|}{ Swedish Holstein } \\
\hline AFR & Lact 1 & $0.42(0.08)$ & $0.59(0.07)$ & $0.12(<0.01)$ & $0.37(0.06)$ & 0.52 & 0.89 \\
\hline \multirow[t]{2}{*}{$\mathrm{BT}$} & Lact 1 & $0.80(0.19)$ & $2.12(0.18)$ & $0.96(<0.01)$ & $0.21(0.05)$ & 0.55 & 0.89 \\
\hline & Lact $2+3$ & $0.93(0.26)$ & $1.71(0.23)$ & $1.16(<0.01)$ & $0.24(0.07)$ & 0.45 & 0.69 \\
\hline \multirow[t]{2}{*}{ MI } & Lact 1 & $1.85(0.40)$ & $3.52(0.35)$ & $1.79(<0.01)$ & $0.26(0.05)$ & 0.49 & 0.75 \\
\hline & Lact $2+3$ & $1.21(0.37)$ & $3.03(0.34)$ & $2.72(<0.01)$ & $0.17(0.05)$ & 0.44 & 0.61 \\
\hline \multicolumn{8}{|c|}{ Swedish Red } \\
\hline \multirow[t]{2}{*}{ AFR } & Lact 1 & $0.28(0.06)$ & $0.40(0.05)$ & $0.08(<0.01)$ & $0.37(0.07)$ & 0.52 & 0.89 \\
\hline & Lact $2+3$ & $0.41(0.08)$ & $0.31(0.06)$ & $0.13(<0.01)$ & $0.48(0.08)$ & 0.37 & 0.85 \\
\hline \multirow[t]{2}{*}{$\mathrm{BT}$} & Lact 1 & $1.67(0.30)$ & $1.73(0.23)$ & $0.94(<0.01)$ & $0.38(0.06)$ & 0.40 & 0.78 \\
\hline & Lact $2+3$ & $1.90(0.33)$ & $1.17(0.25)$ & $1.22(<0.01)$ & $0.44(0.07)$ & 0.27 & 0.72 \\
\hline \multirow[t]{2}{*}{ MI } & Lact 1 & $0.65(0.26)$ & $5.05(0.29)$ & $1.69(<0.01)$ & $0.09(0.03)$ & 0.68 & 0.77 \\
\hline & Lact $2+3$ & $1.46(0.34)$ & $2.36(0.28)$ & $2.43(<0.01)$ & $0.23(0.05)$ & 0.38 & 0.61 \\
\hline
\end{tabular}

${ }^{1} \mathrm{AFR}=$ average flow rate $(\mathrm{kg} / \mathrm{min}) ; \mathrm{BT}=$ box time $(\mathrm{min}) ; \mathrm{MI}=$ milking interval $(\mathrm{h}) ; \mathrm{NoM}=$ number of milkings. 
came from commercial dairy herds using AMS. However, this is the only study with a genetic approach. Previous genetic studies that published results for milk flow rate in AMS are based on data from research farms (Hogeveen et al., 2001; Gäde et al., 2006; Løvendahl et al., 2011). Both Hogeveen et al. (2001) and Gäde et al. (2006) reported an average flow rate of $2.5 \mathrm{~kg} / \mathrm{min}$ for Holstein cows compared with 3 to $4 \mathrm{~kg} / \mathrm{min}$ in the present study. However, Hogeveen et al. (2001) calculated the AFR as the ratio between MY and milk flow time, where the milk flow time was defined as the time between the start of milk flow in the electronic milk meter and the detachment of the last teat cup. In the present study, the AFR was measured for each quarter separately and then added to AFR for the whole udder, which means that the flow rate is measured only during the time when each quarter actually is milked. A corresponding estimate of the AFR as presented by Hogeveen et al. (2001) would in the current study be 2.6 $\mathrm{kg} / \mathrm{min}$ for $\mathrm{SH}$ in first lactation, based on the average MY $(12.10 \mathrm{~kg})$ divided by the average MT (4.58 min), which is in agreement with earlier studies. Løvendahl et al. (2011) found an AFR of about $0.8 \mathrm{~kg} / \mathrm{min}$ per udder quarter, which, when adding the 4 quarters to receive the flow rate for the whole udder, agrees well with the results from the present study.

The time each cow spends in the milking box is an important parameter for the cow traffic and for the AMS to be economically efficient. In the present study, the average BT ranged between 7.2 and 7.8 min per milking, which is comparable with 7.4 min reported by Castro et al. (2012), but about a minute longer than the $6.3 \mathrm{~min}$ reported by André et al. (2010). A reason for the shorter visit time in the box reported in the latter study could be that their data came from a research farm, where the animals were grouped into 5 groups managed as different herds and a data collection period of $1 \mathrm{wk}$, whereas the present study as well as that of Castro et al. (2012) are based on commercial farm data collected during 1 or more years. The BT includes, in addition to the time for the milking, also the time needed for identification, udder preparation, and teat cup attachment, teat disinfection, and cluster cleaning. In the present study, descriptive statistics are also reported for the actual milking time, which ranged between 4.6 and 5.2 min per milking. To our knowledge, no other studies have reported results on both of these traits, but for MT, corresponding figures from Hogeveen et al. (2001) and Gäde et al. (2006) were 5.0 and 5.7 min per milking in the AMS.

The main difference between AMS and conventional milking parlors is that the cows decide when and how often to be milked (within certain limits). In the present study, both the number of milkings per cow and day and the milking interval (measured as the time between the beginnings of 2 consecutive milkings) were recorded. The average NoM of 2.4 to 2.5 milkings per day were comparable, or slightly lower, than previously reported on milking frequencies [for example, 2.5 milkings per day by Nixon et al. (2009), about 2.9 milkings per day by Løvendahl et al. (2011), and 2.7 milkings per day by Castro et al. (2012)]. The average MI in the present study, ranging from 9.6 to $10.0 \mathrm{~h}$, were slightly higher than $9.2 \mathrm{~h}$ reported by Hogeveen et al. (2001), but slightly lower than $10.2 \mathrm{~h}$ reported by André et al. (2010).

\section{Nongenetic Factors and Effects to Consider in the Statistical Model}

The traditionally considered fixed effects of HYS and lactation stage were important to include in the analysis, although the inclusion of MY as a covariate had the greatest influence on the results. It could be questioned whether an adjustment of milkability for MY should be done, as it may be genetically correlated to milkability. However, MY varies considerably between milkings due to when the milking takes place and how often the cow is milked. Preliminary analyses also showed that inclusion of MY as a regression clearly reduced the error variance and increased the heritability of AFR (from 0.33 to 0.37 ) compared with an analysis without considering the effect of MY. Furthermore, preliminary analyses showed that the genetic correlation of MY with AFR was around zero, whereas the genetic correlation of MY with BT was about 0.4. It could also be questioned whether the effect of HYS should be considered to be fixed or random. Because of the limited number of herds and observation years, we decided to treat it as a fixed effect for this particular study.

\section{Heritabilities and Repeatabilities of Milkability Traits}

Only a few studies have reported heritability estimates for milkability traits in AMS. Heritabilities estimated for flow rate $(0.37-0.48)$ in the present study were in the same range, or slightly lower, than those reported for AMS data from research farms, which likely operate under more standardized environmental conditions. Gäde et al. (2006) reported a heritability of 0.49 and Løvendahl et al. (2011) estimated a heritability of 0.57 . However, our results are in the same range as heritability estimates from objectively measured flow rates in conventional milking parlors [e.g., a heritability of 0.28 was reported by Rensing and Ruten (2005), 0.42 by Gäde et al. (2007), and 0.27 by Laureano et al. (2012)]. Older reported milkability heritabilities were mainly based on subjective scoring of the trait, which 
in general, has shown lower heritability than objectively measured milkability (e.g., Rensing and Ruten, 2005).

Løvendahl et al. (2011) reported a heritability of 0.30 for BT per day, which is in between the heritability of 0.21 to 0.24 and 0.38 to 0.44 estimated for SH and SR, respectively, for BT in the present study. To our knowledge, these are the only reported estimates of heritability for this trait. A trait correlated with BT is total milking time, which can be measured both in AMS and in conventional milking parlors. Reported heritability estimates of this trait varies a lot between different studies, from 0.11 (Gray et al., 2011) to 0.37-0.38 (Gäde et al., 2006, 2007; Aydin et al., 2008).

The heritability estimates for MI $(0.09-0.26)$ in the present study were in the range of previously published estimates for milking frequency in AMS. König et al. (2006) estimated a heritability of 0.18, Nixon et al. (2009) reported heritabilities in the range from 0.02 to 0.14 and Løvendahl et al. (2011) estimated a heritability of 0.17 . The heritability estimates indicate that selection against long MI may be possible if the trait were included in a selection index. However, selection for shorter MI does not necessarily mean higher milk production per AMS. According to de Koning and Ouweltjes (2000) the lower milking frequency meant that the cows gave more milk per milking and because BT was less, more cows could be milked per AMS.

The results in the present study were consistent over the whole lactation, with repeatabilities of 0.85 to 0.88 for flow rate of both breeds, and slightly less for BT. These values are comparable with, or higher than, the results from the German AMS study of data from a research farm by Gäde et al. (2006). They reported repeatabilities of 0.76 for AFR and 0.73 for MT. The repeatability coefficients from their and our AMS study are higher than published results for milk flow rates in conventional milking parlors, as reported by Rensing and Ruten (2005) and Laureano et al. (2012): 0.47 and 0.66 , respectively. The difference could be explained by the fact that the estimates from the AMS studies were based on many close observations per cow, whereas the studies from conventional milking parlors were based on less frequent (maximum of 10) observations per cow and lactation. The high repeatabilities for milkability traits, especially for AFR, indicate that it should not be necessary to collect as many observations per animal to be able to achieve accurate information on each cow.

\section{Feasibility of Using AMS Data and Choice of Milkability Traits}

The AMS records information about every milking, regardless of the quality of the milking. Thus, the data needs thorough editing before it is useful for genetic analysis. Although the AMS have code systems that for each milking show if the milking is regarded as complete or not, it is still necessary to further edit the data to exclude observations clearly inconsistent with the normal patterns of variation (edit step 4). By setting certain criteria (e.g., for incomplete milkings) and excluding the observations that do not fit, a risk exists to create a bias in the estimates. However, the high repeatability coefficients, the large number of remaining observations per cow, and the normality of the variation in the observed traits after exclusion of observations that did not fit the set criteria led us to the conclusion that no important bias existed.

Another challenge in the editing process was to connect the data from the AMS with pedigree information. For data to be valuable for genetic analysis, it must be possible to match them with the identification system used in the national recording system. The experiences of the data quality and editing procedures show that, under the conditions Swedish AMS farms operated during the years of data collection with fast increasing herd sizes and new milking systems, almost half of the data and about a quarter of the cows had to be excluded due to incomplete or inconsistent information. Still, much more data are available than what is needed for accurate genetic parameter estimations. After the editing process, the remaining data set included, on average, 340 and 392 observations between 8 and 330 DIM per cow for first-lactation SH and SR cows, respectively. For second and third lactations together, the number of observations per cow was 455 and 539 for the 2 breeds. Heritabilities of 0.4 to 0.5 and repeatabilities of more than 0.8 for flow rate mean that accurate prediction of breeding values of individual cows could easily be obtained by applying BLUP animal models. In fact, when only the first 100 observations per cow were included in the analysis, results showed practically no increase in the standard errors for the heritability estimates of the milkability traits compared with when the full data set was used [0.064 vs. 0.066 for AFR and 0.047 vs. 0.054 for BT (figures not shown in tables)]. Further studies will be needed on which observations should be used in genetic evaluations, when also in-line data from conventional milking parlors, which include the majority of cows in Sweden, must be included to get national coverage of a genetic evaluation system. Detailed studies on best models to use for the evaluations will then also be needed.

The variable with notably low estimates both concerning heritability and repeatability is NoM. This is the only noncontinuous variable in the current study, defined in a way that generates rounding errors. Hence, NoM does not seem suitable for genetic analyses, and MI may also be questionable to use. For the final choice 
of milkability traits to use, it is also important to investigate the relationships between milkability traits and the potential risks of cows being affected with mastitis.

\section{CONCLUSIONS}

Automatic milking system data from commercial herds are very useful for genetic analysis of milkability traits. Extensive data editing is necessary, but more than enough accurate data are still available for analyses. Flow rate has previously been the most common trait to use as a proxy for milkability. However, BT is likely the economically most important trait in AMS. Heritabilities are moderate to high for milk flow rate as well as for BT. Repeatabilities of records are generally high for the same traits. Further analyses are suggested to clarify what could be an efficient model for genetic evaluation purposes, when AMS data are combined with in-line recorded milkability observations from conventional milking parlors. For final decisions on the choice of the best measures for improvement of milkability, studies on relationships between milkability traits and risk of mastitis are needed.

\section{ACKNOWLEDGMENTS}

The authors acknowledge the Swedish Farmers' Foundation for Agricultural Research (Stockholm, Sweden) for their financial support. DeLaval (Tumba, Sweden) generously enabled contact with dairy herds using AMS. Owners of the included dairy herds and Växa Sweden (Stockholm, Sweden; previously named the Swedish Dairy Association) are gratefully acknowledged for providing material for the study.

\section{REFERENCES}

André, G., P. B. M. Berentsen, B. Engel, C. J. A. M. de Koning, and A. G. J. M. Oude Lansink. 2010. Increasing the revenues from automatic milking by using individual variation in milking characteristics. J. Dairy Sci. 93:942-953.

Aydin, R., M. Yanar, O. Güler, S. Yüksel, F. Ugar, and L. Turgut. 2008. Study on milkability traits in Brown Swiss cows reared Eastern region of Turkey. J. Anim. Vet. Advances 7:1218-1222.

Castro, A., J. M. Pereira, C. Amiama, and J. Bueno. 2012. Estimating efficiency in automatic milking systems. J. Dairy Sci. 95:929-936.

de Koning, K., and W. Ouweltjes. 2000. Maximising the milking capacity of an automatic milking system. Pages 38-46 in Robotic Milking: Proc. Int. Symp., Lelystad, the Netherlands. Wageningen Academic Publishers, Wageningen, the Netherlands.

Gäde, S., E. Stamer, J. Bennewitz, W. Junge, and E. Kalm. 2007. Genetic parameters for serial, automatically recorded milkability and its relationship to udder health in dairy cattle. Animal 1:787-796.
Gäde, S., E. Stamer, W. Junge, and E. Kalm. 2006. Estimates of genetic parameters for milkability from automatic milking. Livest. Sci. 104:135-146.

Gray, K. A., F. Vacirca, A. Bagnato, A. B. Samoré, A. Rossoni, and C. Maltecca. 2011. Genetic evaluations for measures of the milkflow curve in the Italian Brown Swiss population. J. Dairy Sci. 94:960-970.

Hogeveen, H., W. Ouweltjes, C. J. A. M. de Koning, and K. Stelwagen. 2001. Milking interval, milk production and milk flow-rate in an automatic milking system. Livest. Prod. Sci. 72:157-167.

Jensen, J., E. A. Mäntysaari, P. Madsen, and R. Thompson. 1997. Residual maximum likelihood estimation of (co)variance components in multivariate mixed linear models using average information. J. Indian Soc. Agric. Stat. 49:215-236.

Johansson, I. 1961. Udder development and milking rate. Pages 124129 in Genetic Aspects of Dairy Cattle Breeding. University of Illinois Press, Urbana.

König, S., F. Köhn, K. Kuwan, H. Simianer, and M. Gauly. 2006. Use of repeated measures analysis for evaluation of genetic background of dairy cattle behavior in automatic milking systems. J. Dairy Sci. 89:3636-3644

Laureano, M. M. M., A. B. Bignardi, L. El Faro, V. L. Cardoso, and L. G. Albuquerque. 2012. Genetic parameters for first lactation test-day milk flow in Holstein cows. Animal 6:31-35.

Lawstuen, D. D., L. B. Hansen, G. R. Steuernagel, and L. P. Johnson. 1988. Management traits scored by dairy producers. J. Dairy Sci. 71:788-799.

Løvendahl, P., J. Lassen, and M. G. G. Chagunda. 2011. Genetic analysis of milkability, milking frequency, milk yield and composition in automatically milked cows. Page 80 in Book of Abstracts of 62nd Annu. Meet. Eur. Fed. Anim. Sci., Stavanger, Norway. Wageningen Academic Publishers, Wageningen, the Netherlands.

Lundberg, M. 1974. Sambandet mellan mjölkningsegenskaper och mastit (Relationships between some milking characteristics and the resistance to mastitis). MS Thesis. Swedish University of Agricultural Sciences, Department of Animal Breeding and Genetics, Uppsala, Sweden.

Madsen, P. 2010. DMU trace, A program to trace the pedigree for a sub set of animals from a larger pedigree file. Mimeograph. Faculty Agricultural Sciences, University of Aarhus, Dept. of Genetics and Biotechnology, Research Centre Foulum, Denmark.

Madsen, P., and J. Jensen. 2007. A User's Guide to DMU, A Package for Analyzing Multivariate Mixed Models. Version 6, release 4.7. University of Aarhus, Faculty Agricultural Sciences, Dept. of Genetics and Biotechnology, Research Centre Foulum, Denmark.

Meyer, K., and E. B. Burnside. 1987. Scope for a subjective assessment of milking speed. J. Dairy Sci. 70:1061-1068.

Nixon, M., J. Bohmanova, J. Jamrozik, L. R. Schaeffer, K. Hand, and F. Miglior. 2009. Genetic parameters of milking frequency and milk production traits in Canadian Holsteins milked by an automated milking system. J. Dairy Sci. 92:3422-3430.

Rensing, S., and W. Ruten. 2005. Genetic evaluation for milking speed in German Holstein population using different traits in a multiple trait repeatability model. Interbull Bull. 33:163-166.

Sewalem, A., F. Miglior, and G. J. Kistemaker. 2011. Short communication: Genetic parameters of milking temperament and milking speed in Canadian Holsteins. J. Dairy Sci. 94:512-516.

Vicario, D., L. Degano, and P. Carnier. 2006. Genetic evaluation for milkability using subjective and measured observations in Italian dual purpose Simmental Cows. Interbull Bull. 35:53-57. 